\section{Pieces of action}

Sandy Grimwade reports from Washington on some of the non-legislative developments concerning recombinant $D N A$ research

Although much of the attention of the followers of the recombinant DNA debate has focused on the progress of the controlling legislation at present under consideration in Congress, activity in research labs and on campuses has not been completely stilled. A major supplier of laboratory chemicals has taken some unprecedented steps to control the use of its restriction enzymes-the enzymes which are used in the preparation of recombinant DNA molecules. A Maryland lawyer has sued the National Institutes of Health (NIH) on behalf of his son to postpone recombinant DNA experiments which he claims are at present illegal. And another group of scientists has petitioned Congress over the proposed legislation.

The firm which has taken a step practically guaranteed to lose it customers while bringing praise from those who favour a cautious approach to recombinant DNA research is Miles Laboratories Inc. Miles has been an important supplier of restriction enzymes for several years, and last year sponsored a symposium on recombinant DNA research. In themselves restriction enzymes can cause no hazard; a competent molecular biologist, moreover, would be able to prepare a private supply with a week or so of work. Miles now requires its customers to appoint a control officer who will be responsible for ensuring that its reagents are used in accordance with the NIH guidelines, and who must sign all orders for such reagents.

A spokesman for Miles said that the firm had taken this step on both moral and legal grounds, and that the restriction will be kept in force until the federal legislation now pending becomes law. Miles is applying this condition to all sales of restriction enzymes on the advice of its lawyers so that the entire burden of responsibility for their use is shifted to the customers. The spokesman admitted that the reaction from scientists to this additional bureaucratic requirement had not been entirely favourable. Its action is unilateral; other companies in the business are apparently not planning to follow suit.

The action of the attorney in Frederick, Maryland, who filed suit under the National Environmental Protection Act on behalf of his 2-yearold son against NIH, was aimed at halting experiments planned to take place at Fort Detrick before publication of an Environmental Impact Statement (EIS). The experiments, which would involve the splicing of segments of the mouse polyoma virus genome as well as the whole genome into plasmids and cloning in E. coli, would under the NIH guidelines require the highest level of physical containment, the P4 level. The objective of the experiments is to discover whether the cloned gene segments of the polyoma virus, which causes cancer in mice but has no effect in humans, are expressed in $E$. coli and whether the gene products can raise antibodies in mice treated with the $E$. coli clones.

NIH have agreed to produce an EIS in 30 days, although it is not clear at this point whether the statement will address the potential impact of this particular experiment or recombinant DNA experimentation as a whole. The attorney, Ferdinand Mack, sees the NIH action as a concession that they were ignoring the law requiring the publication of an EIS. In fact the EIS from NIH on the complete recombinant DNA guidelines has been hanging fire for over a year now, a point which does not follow the letter of the National Environment Protection Act. Friends of the Earth have filed a separate injunction enjoining a halt to all federally funded research in this area until the EIS is published.

The latest petition from scientists follows the statement about a month ago from the Gordon Conference on Nucleic Acids urging Congress to drop or tone down the proposed legislation. Signed by 140 scientists attending the Conference on Biological Regulatory Mechanisms- $85 \%$ of those attending - the new statement was sent to members of Congress as part of a latestarting but vigorous effort by the proponents of recombinant DNA research to urge more lenient legislation.

\title{
Scanning the universe
}

$\mathrm{X}$-RAY astronomers are not having much luck at the moment. ESA's decision to schedule Exosat on the Ariane launcher upset the European space community, less because of Ariane's unknown reliability than because of the spectre of budget cuts for other projects and an almost certain delayed start to the mission. Though US astronomers have fared no better in recent months, some improvement may now come with the first satellite of the HEAO mission, which NASA expects to launch this week.

The High Energy Astronomy Observatory (HEAO) project was initiated in 1968. Budget cuts have since halved its size, but still the three-satellite mission involves the heaviest Earth-orbiting satellites ever launched. NASA had hoped to launch the first satellite, HEAO-A, on 15 April, but problems with the spacecraft's gyroscopes caused cancellation at the last moment; re-design and qualification of the gyros have now been completed. Though a launch scheduled for 30 June was missed, lift-off is fixed for the early morning of 12 August.

The HEAO observatories are designed as sensitive high-resolution detectors of $\mathrm{X}$-rays and $\gamma$-rays. Building on the success and experience of such missions as Uhuru, Copernicus, Ariel V and SAS-3, HEAO could help resolve controversies over the existence of black holes and the nature of quasars, pulsars and X-ray bursters. No one commits $\$ 237$ million solely to fashion, however, and the HEAO mission has a solid, professional set of scientific objectives to pursue.

HEAO-A is an all-sky X-ray survey mission. A circular, $445-\mathrm{km}$ high orbit will place it above the absorbing atmosphere and below the damaging radiation belts. During its six-month lifetime it will scan the complete sky and systematically

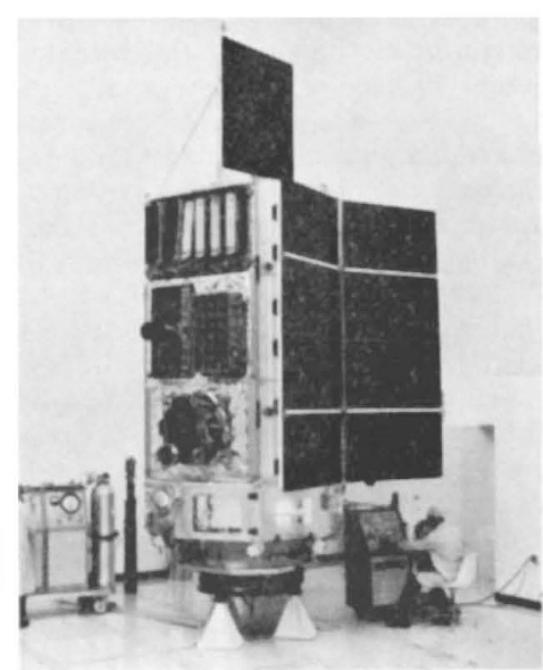

map both discrete X-ray sources and diffuse X-ray emission and absorption. The four experiments on-board provide high resolution (up to 5 arc-seconds) for position and size determinations and good time resolution for investigating the complex behaviour of variable sources. Crude spectral data will also be obtained.

HEAO-B is due for launch in 1978 . Containing a wide-aperture imaging $\mathrm{X}$ ray telescope with a sensitivity 10,000 times greater than any previously flown, it will latch on to specific sources of interest pinned down by HEAO-A and study them in great detail. The mission lifetime is estimated as one year. HEAO-C, another all-sky survey satellite and due for launch in 1979, will systematically scan for cosmic and $\gamma$-ray sources.

Stuart Sharrock 